\title{
Transferability and polymorphism of barley EST-SSR markers used for phylogenetic analysis in Hordeum chilense
}

\author{
Almudena Castillo1, Hikmet Budak², Rajeev K Varshney3,5, Gabriel Dorado4, \\ Andreas Graner ${ }^{5}$ and Pilar Hernandez*1
}

Address: ${ }^{1}$ Institute for Sustainable Agriculture (IAS-CSIC), Alameda del Obispo s/n, 14080 Córdoba, Spain, ${ }^{2}$ Sabanci University, Engineering and Natural Sciences, Biological Science and Bioengineering Program, Orhanli 34956 Tuzla-Istanbul, Turkey, ${ }^{3}$ International Crops Research Institute for the Semi-Arid Tropics (ICRISAT), Patancheru - 502 324, Andhra Pradesh, India, ${ }^{4}$ Dep. Bioquímica y Biología Molecular, Campus Rabanales, C6-1-E17, Universidad de Córdoba, 14071 Córdoba, Spain and ${ }^{5}$ Leibniz Institute of Plant Genetics and Crop Plant Research (IPK), Corrensstrasse 3, D-06466 Gatersleben, Germany

Email:Almudena Castillo - almudena.castillo@ias.csic.es; Hikmet Budak - budak@sabanciuniv.edu; Rajeev K Varshney - r.k.varshney@cgiar.org; Gabriel Dorado - bb1dopeg@uco.es; Andreas Graner - graner@ipk-gatersleben.de; Pilar Hernandez* - ge1hemop@uco.es

* Corresponding author

Published: 28 September 2008

BMC Plant Biology 2008, 8:97 doi:1 0.1 | 86/I47|-2229-8-97
Received: 27 June 2008

Accepted: 28 September 2008

This article is available from: http://www.biomedcentral.com/I47I-2229/8/97

(C) 2008 Castillo et al; licensee BioMed Central Ltd.

This is an Open Access article distributed under the terms of the Creative Commons Attribution License (http://creativecommons.org/licenses/by/2.0), which permits unrestricted use, distribution, and reproduction in any medium, provided the original work is properly cited.

\begin{abstract}
Background: Hordeum chilense, a native South American diploid wild barley, is a potential source of useful genes for cereal breeding. The use of this wild species to increase genetic variation in cereals will be greatly facilitated by marker-assisted selection. Different economically feasible approaches have been undertaken for this wild species with limited direct agricultural use in a search for suitable and cost-effective markers. The availability of Expressed Sequence Tags (EST) derived microsatellites or simple sequence repeat (SSR) markers, commonly called as EST-SSRs, for barley (Hordeum vulgare) represents a promising source to increase the number of genetic markers available for the $H$. chilense genome.

Results: All of the 82 barley EST-derived SSR primer pairs tested for transferability to $H$. chilense amplified products of correct size from this species. Of these 82 barley EST-SSRs, 2 I (26\%) showed polymorphism among $H$. chilense lines. Identified polymorphic markers were used to test the transferability and polymorphism in other Poaceae family species with the aim of establishing $H$. chilense phylogenetic relationships. Triticum aestivum- $H$. chilense addition lines allowed us to determine the chromosomal localizations of EST-SSR markers and confirm conservation of the linkage group.

Conclusion: From the present study a set of 21 polymorphic EST-SSR markers have been identified to be useful for diversity analysis of $H$. chilense, related wild barleys like $H$. murinum, and for wheat marker-assisted introgression breeding. Across-genera transferability of the barley ESTSSR markers has allowed phylogenetic inference within the Triticeae complex.
\end{abstract}

\section{Background}

Wild species constitute a potential source of genetic variation for cultivated species. Besides, they can be analyzed to answer the long-lasting questions concerning the origins, evolution and spread of major agricultural crops of the world. Recently, there has been considerable progress 
in plant genomics, leading to novel molecular breeding tools to reduce the costs and to simplify the assays. Plant genome research has been focused on the major crops and model species and a vast amount of genomic information has been accumulated. This information will provide an opportunity to use it as sources of information for thousands of minor grass species [1].

Hordeum chilense Roem et Schultes is a native South American diploid perennial wild barley $(2 \mathrm{n}=2 \mathrm{x}=14)$, included in the section Anisolepsis [2]. It belongs to a heterogeneous group of South American Hordeum species and it is one of the species of the genus Hordeum with a high potential for cereal breeding purposes, given its high crossability with other members of the Triticeae tribe. $H$. chilense was used to obtain fertile amphiploids with wheat of different ploidy levels (diploid, tetraploid and hexaploid). These amphiploids were named Tritordeum and are the basic genetic material for using $H$. chilense genetic variability in wheat breeding [3]. H. chilense has agronomically interesting characteristics, like high carotenoid content, biotic and abiotic stress resistance, and variability for seed storage proteins [4]. A new cytoplasmic male sterility (CMS) source in bread wheat using the cytoplasm of $H$. chilense has also been reported [5].

The characterization of genetic variability in wild species like H. chilense and the development of tools to introduce it into cultivated crops are important plant breeding goals. The analysis of DNA sequence variation is of major importance in genetic studies. In this context, molecular markers are useful tools for assaying genetic variation, and have greatly enhanced the genetic analysis of crop plants. High development costs make it impractical to develop molecular markers directly from wild species like $H$. chilense. However, if markers developed in related crop species can be used, genetic analysis of $H$. chilense could be advanced rapidly [6].

Several types of molecular markers, including Random Amplified Polymorphic DNA (RAPD) and Sequence Characterized Amplified Regions (SCARs) $[7,8]$ have been developed de novo for $H$. chilense. Comparative genetic analysis has been established in the grass genomes [9] showing significant conservation of marker and gene order across the cereal crops. On this basis, Sequence Tagged Sites (STSs) and microsatellites or simple sequence repeats (SSRs) were transferred from wheat and barley to $H$. chilense $[10,11]$. The SSR markers have been the molecular markers of choice for molecular breeders due to their codominant inheritance, multi-allelic nature and easy detection [12]. Recent studies have used the increase on the availability of large numbers of Expressed Sequence Tags (ESTs) in public databases, to the search for SSRs present in ESTs i.e. in barley [13], sugarcane [14], bread wheat [15], apricot and grape [16], rice [17] and Vaccinium [18].

Across-species transferability of SSRs derived from EST databases is greater than that of SSRs derived from enriched genomic DNA libraries, as they originate from expressed regions and therefore they are more conserved across a number of related species than non-coding regions [19]. They have shown to be useful for comparative mapping across species, comparative genomics, and evolutionary studies and they have been shown to posses a higher potential for inter-specific transferability than genomic SSRs $[15,16,20-23]$. On the other hand, they are expected to be less polymorphic within the species due to its conserved nature [19]. In summary, EST-SSR has provided a valuable source of new PCR-based molecular markers in cereal crops.

We have tested the transferability of 82 EST-SSR markers developed in barley [24,25], and their potential use as new molecular tools for introgression, variability and phylogenetic analysis of the $H$. chilense genome. The chromosomal locations of the transferred and polymorphic EST-SSRs were assigned using wheat chromosome addition lines [26].

The grass family (Poaceae) is formed by 600 genera and between 9,000 to 10,000 species of grasses. This family comprises the most important cultivated crops like wheat, barley, rye, and rice [27]. H. chilense belongs to the Poaceae family, Triticeae tribe, genus Hordeum. Previous cytogenetic work suggested that $H$. chilense chromosomes are more similar to the D- than to the A- or B-genomes of wheat [28]. The phylogenetic relationships of $H$. chilense with respect to Triticum and Hordeum have not been studied in detail so far. For this reason, the set of EST-SSR primers that successfully amplified $H$. chilense and showed polymorphism was further tested for transferability to other species of the Poaceae family with the aim to investigate phylogenetic relationships.

\section{Methods}

\section{Plant material and DNA extraction}

Two accessions (H1 and H7) of H. chilense and one genotype ('Barke') of H. vulgare were used for the initial transferability analysis of 82 barley EST-derived SSR-markers. Barke was included as standard because this cultivar was used to construct the EST libraries screened to search for SSRs [29]. A set of wheat (cv. 'Chinese Spring')/H. chilense accession $\mathrm{H} 1$ addition lines [26] and their wheat and wild barley donors were used for the chromosome location of the 21 transferred and polymorphic EST-SSR markers. For the phylogenetic analysis, two hexaploid wheat (Triticum aestivum L.) accessions ('T21' cv. 'Chinese Spring' and 'T20'), two tetraploid wheat (T. durum) accessions ('T22' 
and 'T81' cv. 'Yavaros'), the diploid wheat (T. tauschii) accession ('T6'), two T. urartu accessions ('T485' and 'T486'), two barley (H. vulgare) cultivars ('Betzes' and 'Barke'), two $H$. chilense accessions (H1 and H7), one $H$. murinum and two Brachypodium distachyon L. accessions ('Bd1' and 'Bd6') were evaluated.

Total genomic DNA was isolated from young frozen leaf tissue using the CTAB method of Murray and Thompson [30] as modified by Hernandez et al. [31]. The concentration of each sample was estimated by comparing band intensity with lambda DNA digests of known concentrations under UV light, after $0.8 \%(\mathrm{w} / \mathrm{v})$ agarose gel electrophoresis and ethidium bromide staining.

\section{Amplification and transferability of barley EST-SSR markers}

A set of 82 barley EST-derived SSR markers developed by Varshney et al. [25] and uniformly distributed across the H. vulgare chromosomes were tested for amplification of the $H$. chilense DNA from lines $\mathrm{H} 1$ and $\mathrm{H} 7 \mathrm{using} H$. vulgare cV. 'Barke' as control. For each EST-SSR, the forward primer was labeled with one fluorescent dye for detection on an ABI Prism 310 Genetic Analyzer from Applied Biosystems (Foster City, CA, USA). The PCR amplification was carried out using a GeneAmp PCR System 9700 in 20 $\mu \mathrm{l}$ reactions consisting of a $1 \times$ PCR buffer including 1.5 $\mu \mathrm{M} \mathrm{MgCl}_{2}, 200 \mu \mathrm{M}$ dNTPs, $250 \mathrm{nM}$ of each primer, 0.25 U of Taq Gold DNA polymerase (PCR cycler and reagents from Applied Biosystems), and 20 ng of genomic DNA. PCR conditions followed a touch-down protocol as described in [24] and [25]: an initial denaturing step of 10 min at $94^{\circ} \mathrm{C}$ was followed by 45 cycles with denaturation at $94^{\circ} \mathrm{C}$ for $30 \mathrm{~s}$ and extension at $72^{\circ} \mathrm{C}$ for $30 \mathrm{~s}$, respectively. The annealing temperature was decreased in $0.5^{\circ} \mathrm{C}$ per cycle, from $60^{\circ} \mathrm{C}$ in the first cycle to $55^{\circ} \mathrm{C}$ after the 10th cycle, and was then kept constant for the remaining 35 cycles (always $30 \mathrm{~s}$ ). After 45 cycles, a final extension step was performed at $72^{\circ} \mathrm{C}$ for $5 \mathrm{~min}$.

Amplification products derived from fluorescently labeled primers were resolved by capillary electrophoresis on the ABI Prism 310 Genetic Analyzer. The fragment sizes were calculated using the computer program GeneScan from the same manufacturer, by comparison with an internal size standard (Figure 1). The presence and pattern of stuttering was locus-specific and was analyzed as an indication of correct locus transferability. For instance, Figure 1 shows the amplification of a barley trinucleotide EST-SSR, with weak -3 bp stutters. The stutters are also present in $H$. chilense lines $\mathrm{H} 1$ and $\mathrm{H} 7$, with a similar pattern (weak -3 bp stutters, as shown in Figure 1). A selection of primer

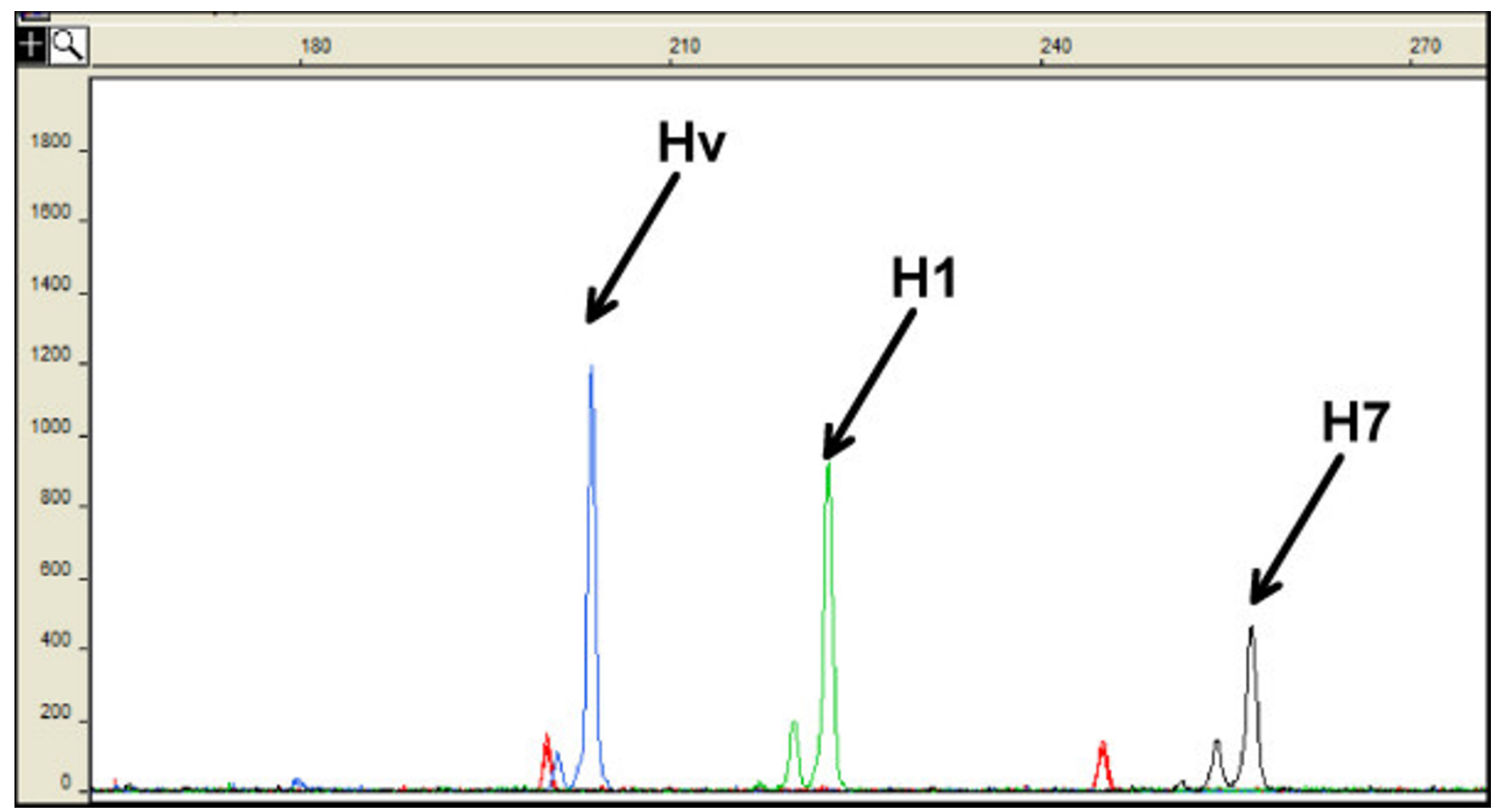

Figure I

Polymorphism in Hordeum chilense lines detected by M7.8 (barley GBMI464) marker of linkage group 7H. Electropherogram obtained on an ABI Prism 310 Genetic Analyzer, showing the polymorphism. $\mathrm{HI}$ and H7: $\mathrm{H}$. chilense lines. Hv: $\mathrm{H}$. vulgare cv. 'Betzes'. 
pairs that showed polymorphism in $H$. chilense lines were tested in the other species using the same PCR conditions. To assign barley EST-SSR markers to $H$. chilense chromosomes, six $T$. aestivum $/ H$. chilense accession $\mathrm{H} 1$ addition lines including a monotelodisomic $1 \mathrm{H}^{\mathrm{ch}} \mathrm{S}$ addition, a ditelosomic addition for $2 \mathrm{H}^{\mathrm{ch}}$ alpha arm, and disomic addition lines for chromosomes $4 \mathrm{H}^{\mathrm{ch}}, 5 \mathrm{H}^{\mathrm{ch}}, 6 \mathrm{H}^{\mathrm{ch}}$ and $7 \mathrm{H}^{\mathrm{ch}}$ were used [26] (Figures 2 and 3). The addition line carrying the chromosome 3 is not available and therefore the assignment of markers to this chromosome was done using the lack of amplification in the other addition lines mentioned above.

\section{Phylogenetic data analysis}

A binary matrix was generated, where the presence or absence of each allele was coded by 1 or 0 respectively. The binary data were used to calculate the distance matrix using the Jaccard's similarity coefficient [32], because the binary information was asymmetric (the shared absence of a given allele did not contribute to genetic similarity, as no null alleles were found). The software package Phylip [33] was used to calculate the genetic relationships by neighbor-joining (NJ) analysis. The reliability and goodness of fit of the dendrogram obtained was tested by bootstrap analysis based on 1,000 permutations, followed by the program Consense module in the software package Phylip. The dendrogram (Figure 4) was constructed using the NJ method with the program TreeView [34]. The tree

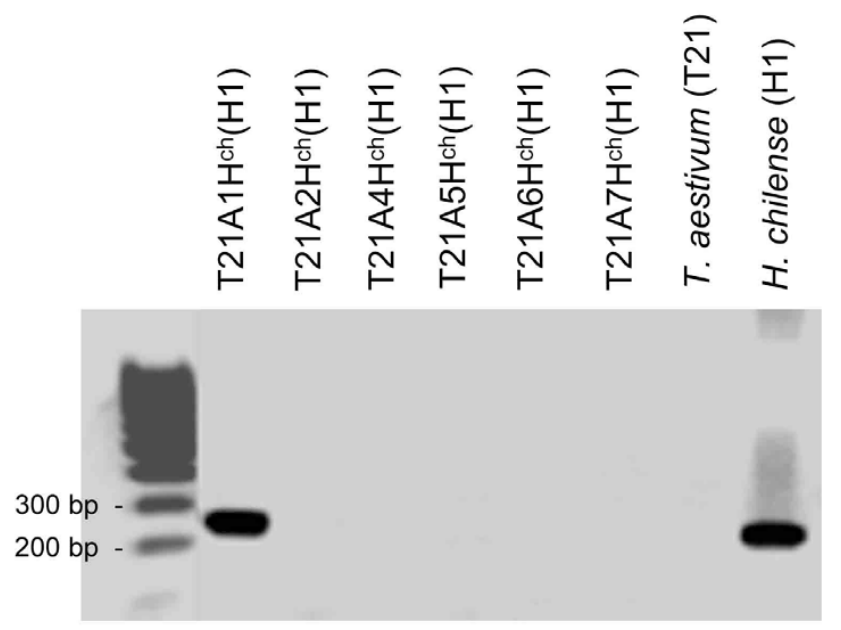

\section{Figure 2}

PCR amplification of marker MI.2 (barley GBM

I 029) marker (IH) in Hordeum chilense lines. The PCR amplification products were segregated on agarose gel electrophoresis and visualized under UV light in the presence of ethidium bromide. Lanes (left to right): T. aestivum accession $\mathrm{T} 2 \mathrm{I}-\mathrm{H}$. chilense accession $\mathrm{HI}$ addition lines ( $\mathrm{IHch}+$ telo, $2 \mathrm{Hch} \alpha, 4 \mathrm{Hch}, 5 \mathrm{Hch}, 6 \mathrm{Hch}$, and $7 \mathrm{Hch}$ ), wheat $\mathrm{T} 2 \mathrm{I}$ parent and $H$. chilense HI parent. was rooted using $B$. distachyon as outgroup. For the phylogenetic analysis, hexaploid wheat allelic data were separated into its three $\mathrm{A}, \mathrm{B}$ and $\mathrm{D}$ genome alleles, and tetraploid wheat allelic data were separated into its two A and $\mathrm{B}$ genome alleles (Figure 4). A second dendrogram (not shown, as the relationships are similar) was obtained only for the species belonging to the Triticeae tribe, using the UPGMA clustering method, as the divergence between these species was quite recent and therefore the molecular clock could be assumed.

\section{Results \\ Amplification and polymorphism of barley EST-SSR markers}

All eighty-two sets of primer pairs from barley EST-SSR markers amplified products within the $H$. chilense genome. The amplification patterns of 28 EST-SSRs were not reliable though. An amplification pattern was considered as not reliable for any of the following four reasons: i) the presence of too many amplification products; ii) the presence of faint bands; iii) the molecular weight of the $H$. chilense amplification product was of a different size range than the $H$. vulgare molecular weight; iv) the $H$. vulgare stuttering profile was not maintained in $H$. chilense. Of the remaining markers, twenty-one primer pairs (26\%) showed polymorphism between $\mathrm{H} 1$ and $\mathrm{H} 7 \mathrm{H}$. chilense lines (Figure 1) and were renamed according to their chromosomal location in $H$. chilense (Table 1$)$. These twentyone primer pairs were tested in the rest of species included in this study (Table 1). From them, 100\% amplified in the H. murinum genome; 19 (90\%) amplified in the T. durum genome; 17 (81\%) amplified the genomes of T. aestivum, T. urartu and T. tauschii, and 16 (76\%) amplified the genome of $B$. distachyon. Primers for three EST-SSR markers (M1.4, M4.1 and M5.6) amplified only one of the two $B$. distachyon accessions tested. Similarly, amplification of the primer pair M1.8 was observed only in one of the two T. urartu and T. durum accessions tested. Primers for 11 EST-SSR markers (M1.2, M2.6, M3.7, M4.1, M4.3, M4.12, M6.5, M6.7, M6.8, M7.8 and M7.9) were monomorphic for any individual species. Five primer pairs detected polymorphism within T. aestivum, four within T. durum, four within T. urartu and six within B. distachyon. All of the 21 primer pairs tested detected interspecies polymorphisms.

\section{Chromosomal location of barley EST-SSR markers in $\mathrm{H}$. chilense}

In order to locate polymorphic barley EST-SSR markers onto the $H$. chilense chromosomes, a set of disomic T. aestivum-H. chilense addition lines [26] was used. All the primer pairs yielded amplification in the expected homoeologous chromosome (Figures 2 and 3). Amplification products that are present in $H$. chilense but absent in wheat, as well as the amplification products of different size were of particular interest, as these markers can be 


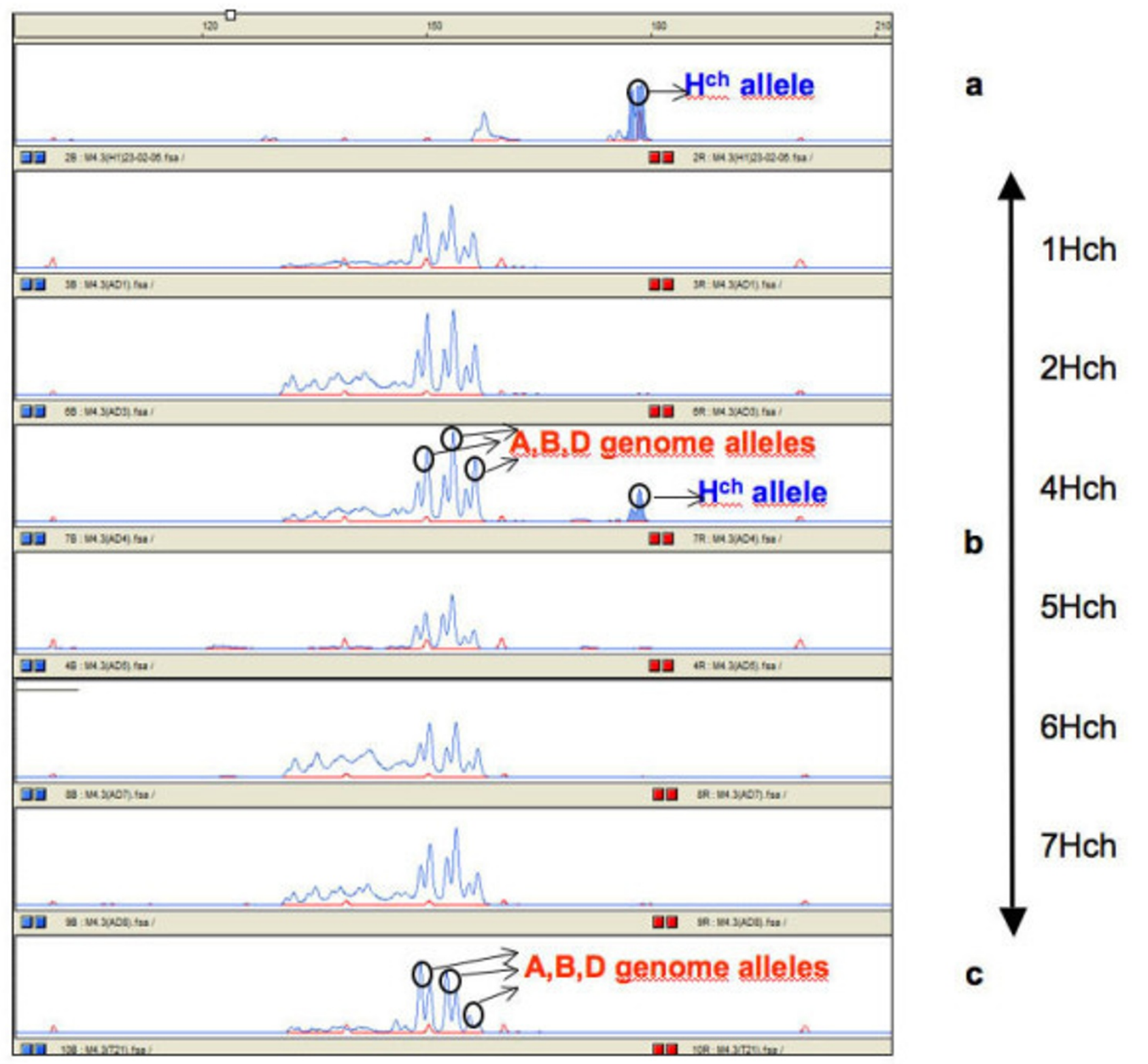

\section{Figure 3}

Amplification profiles of marker M4.3 (barley GBMI 067) marker (4H) in the genomes of Hordeum chilense, Triticum aestivum and disomic chromosome addition lines on the ABI 310 capillary system. (a) $H$. chilense, $H I$ line; (b) T. aestivum accession T2I - H. chilense accession $\mathrm{HI}$ addition lines (IHch + telo, $2 \mathrm{Hch} \alpha, 4 \mathrm{Hch}, 5 \mathrm{Hch}, 6 \mathrm{Hch}$, and $7 \mathrm{Hch}$ ); (c) T. aestivum accession T2I.

used for the detection of $H$. chilense chromosomes in the wheat genetic background for introgression analysis.

Four out of 21 SSR markers amplified a SSR fragment in $H$. chilense, but not in wheat and 15 markers amplified PCR products of a different size range in $H$. chilense and wheat. Therefore, a total of 19 markers were found to be suitable for the analysis of $H$. chilense/wheat introgression.

\section{Phylogenetic relationships}

The potential use of the barley EST-SSR markers to infer the phylogenetic relationships among the species studied (T. aestivum, T. durum, T. urartu, T. tauschii, $H$. vulgare, $H$. murinum, $H$. chilense and B. distachyon) was analyzed using the 13 EST-SSR markers that produced amplification products in all analyzed species. The NJ tree obtained (Figure 4) indicated that all the accessions were clustered 


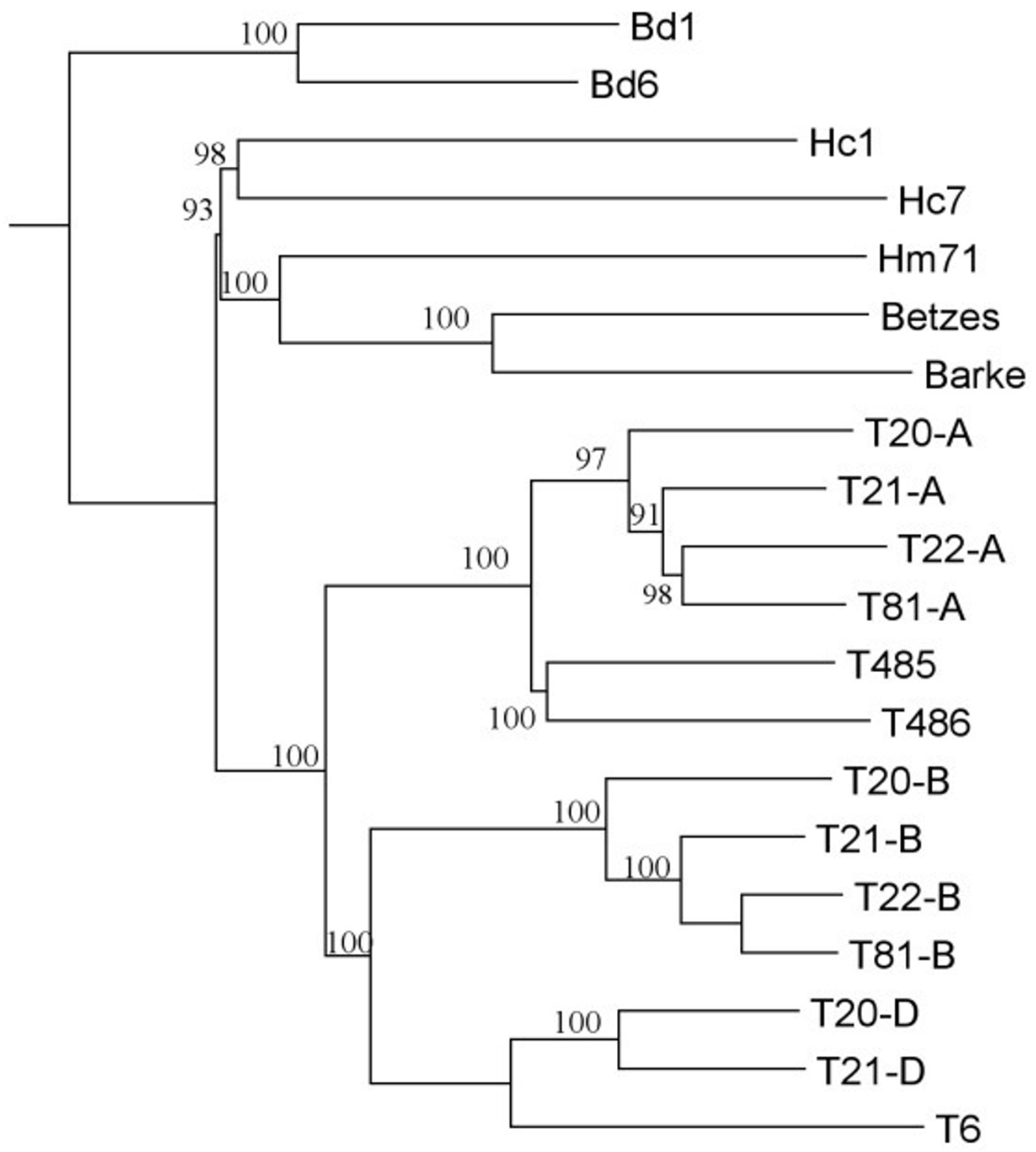

Figure 4

Consensus tree of species reconstructed from $1000 \mathrm{NJ}$ trees obtained from data resampled in a set of 13 ESTSSR markers. The accession codes are: $\mathrm{Hcl}$ and $\mathrm{Hc7}, \mathrm{H}$. chilense; Hm7l, $\mathrm{H}$. murinum; Betzes and Barke, $\mathrm{H}$. vulgare; T20-A, T20-B and T20-D, T. aestivum A- B- and D-genomes; T2I-A, T2I-B and T2I-D, T. aestivum cv. 'Chinese Spring' A- B- and Dgenomes; T22-A and T22-B, T. durum A- and B-genomes; T8I-A and T8I-B, T. durum cv. 'Yavaros'; T485 and T486, T. urartu; T6, T. tauschii; BdI and Bd6, B. distachyon. The numbers at the nodes indicate the percentage number of I.000 bootstrap replications. 
Table I: Intergeneric amplification of selected barley EST-SSRs.

\begin{tabular}{|c|c|c|c|c|c|c|c|c|c|c|}
\hline $\begin{array}{l}\text { H. chilense } \\
\text { marker }\end{array}$ & $\begin{array}{c}H . \text { vulgare } \\
\text { marker }\end{array}$ & Chromosome & H. chilense & H. vulgare & H. murinum & T. durum & T. tauschii & T. urartu & T. aestivum & B. distachyon \\
\hline MI.2* & GBMI029 & I & + & + & + & + & + & + & + & + \\
\hline MI.4 & GBMI002 & 1 & + & + & + & + & + & + & + & + \\
\hline MI.8 & GBMI4II & 1 & + & + & + & + & + & + & - & - \\
\hline M2.5 & GBMI 047 & 2 & + & + & + & + & + & + & - & + \\
\hline$M 2.6^{*}$ & GBMI036 & 2 & + & + & + & + & + & + & + & + \\
\hline M2.II & GBMI462 & 2 & + & + & + & - & - & - & - & - \\
\hline M3.7* & GBMI069 & 3 & + & + & + & + & + & + & + & + \\
\hline M4.I* & GBMI055 & 4 & + & + & + & + & + & + & + & + \\
\hline M4.3* & GBMI067 & 4 & + & + & + & + & + & + & + & + \\
\hline M4.4* & GBMI020 & 4 & + & + & + & + & + & + & + & + \\
\hline M4.10* & GBMI 465 & 4 & + & + & + & + & + & + & + & + \\
\hline M4.12* & GBMI 323 & 4 & + & + & + & + & + & + & + & + \\
\hline M4.15* & GBMI350 & 4 & + & + & + & + & + & + & + & + \\
\hline M5.6* & GBMI064 & 5 & + & + & + & + & + & + & + & + \\
\hline$M 6.5^{*}$ & GBMI008 & 6 & + & + & + & + & + & + & + & + \\
\hline M6.7 & GBMI076 & 6 & + & + & + & + & - & - & + & - \\
\hline M6.8 & GBMI 400 & 6 & + & + & + & + & + & - & + & - \\
\hline M7.I & GBMI060 & 7 & + & + & + & + & - & + & + & - \\
\hline M7.4* & GBMI058 & 7 & + & + & + & + & + & + & + & + \\
\hline M7.8 & GBMI 464 & 7 & + & + & + & + & + & + & - & + \\
\hline M7.9* & GBMI432 & 7 & + & + & + & + & + & + & + & + \\
\hline
\end{tabular}

+ Amplification

- No amplification

* Markers used for the construction of the dendrogram

according to their genome constitution. The bootstrap values are consistent and they are generally higher than $90 \%$. The Triticum species were divided into two groups, one including the D- and B-genome of wheats, and the other including the A-genome of wheat. The Hordeum clade was separated into two clusters: one included the $H$. chilense accessions and the other one included $H$. vulgare and $H$. murinum species. B. distachyon was used as outgroup to root the $\mathrm{NJ}$ tree. The dendrogram obtained by the UPGMA clustering method (not shown) generated similar results to the NJ analysis.

\section{Discussion}

Genomic SSRs have been extensively used for mapping, genetic diversity analysis, and plant breeding, but have a lower rate of transferability across species when compared to the EST-SSR markers. Thus, the latter are a better choice for application in cross-species phylogenetic studies [35], and are also valuable tools for plant breeding, germplasm collection conservation [36], and to measure genetic diversity [37]. More than 500.000 ESTs are presently available for barley and represent an invaluable resource for the development of SSR markers [24,25]. To systematically exploit potentially useful, albeit less studied wild species, like $H$. chilense it would be desirable to use these EST-SSR markers as anchors to the cultivated species genome.
A set of barley genomic SSR markers [38] has been previously tested in $H$. chilense [11]. As expected, the level of transferability $(66 \%)$ of barley EST-SSR markers found in the present work is higher than for the neutral SSRs (54\%). Additionally, the level of polymorphism detected within $H$. chilense with the EST-SSRs $(26 \%)$ is also higher than with the genomic SSRs (6\%).

Our results confirm the high cross-species transferability of the set of 165 barley EST-SSRs tested in wheat, rye and rice [13]. Varshney et al. [13] observed 78.2\% amplicons in wheat, $75.2 \%$ in rye and $42.4 \%$ in rice, demonstrating the high potential of EST-SSR markers for comparative mapping among these species. In the present study, we tested the subset of 21 EST-SSR markers showing higher level of transferability [13] and polymorphism in $H$. chilense lines across genera for phylogenetic inference. We observed 100\% amplification of the selected barley ESTSSR markers in the genome of H. murinum, $90 \%$ amplification in the genome of $T$. durum, $81 \%$ amplification in the genomes of T. aestivum, T. urartu and T. tauschii and $76 \%$ amplification in the genome of B. distachyon. Our results confirm the general observation that the rate of EST-SSRs transferred across species or genera decays as the species or genera are more phylogenetically distant [19].

On the other hand, the sensibly higher transfer rate to $B$. distachyon than to rice confirms the usefulness of Brachypo- 
dium as a model species for barley and wheat and gave us the species of choice for rooting the phylogenetic tree in the present study. Our results showed a higher transferability of barley EST-SSRs to $H$. chilense than to other wild barley species reported previously [24], where $80 \%$ of examined barley markers were successfully amplified in wild barley accessions and about $60 \%$ of the primers yielded amplification products in wheat and rye. The high transferability among Triticeae species and genera has also been reported for wheat EST-SSR markers. For instance, Tang et al. [39] tested 243 wheat EST-SSR markers, from which $216(88.9 \%)$ produced amplicons in wheat, 211 $(86.8 \%)$ in barley, $187(77.0 \%)$ in rice and $166(68.3 \%)$ in maize. Zhang et al. [40] reported the transferability of bread wheat EST-SSRs to closely related Triticeae species, ranging from $76.7 \%$ for $A$. tauschii to $90.4 \%$ for $T$. durum. The rates were lower for more distant relatives such as barley $(50.4 \%)$ or rice $(28.3 \%)$. Similar results were obtained by Yu et al. [22], who found that a total of $53 \%$ of the wheat EST-SSR markers produced amplicons in barley.

The location of barley EST-SSR on the H. chilense chromosomes was determined by the amplification of the available wheat addition lines. They were all found in the same linkage group as barley, thus corroborating the conserved nature of these markers and their potential use in comparative genomics among species. Conserved chromosome locations, together with strong selection criteria (including similar molecular weight range to the donor species and conserved locus stuttering patterns) make these markers' transferability robust enough for their practical application. Fifteen barley EST-SSR produced amplicons of different size in wheat and $H$. chilense, and four did not amplify in wheat. Therefore, 19 barley EST-SSR markers are useful for wheat- $H$. chilense introgression analysis.

Wheat EST-SSRs have been recently demonstrated useful for phylogenetic analysis among the Triticeae species [23]. One of the aims of this study was to infer phylogenetic relationships among the $H$. chilense genome, the cultivated barley genome and the wheat genomes using barley EST-SSRs (Figure 4). In the obtained dendrogram, the nodes were significantly supported by bootstrap analysis, indicating that there were subgroups that could be clearly separated.

As expected, the $H$. chilense genome was situated in the clade of the Hordeum species, despite the reported cytogenetic similarity with the D genome of wheat [1]. The species $H$. murinum (Xu-genome) was closer to H. vulgare (Igenome) than to $H$. chilense (H-genome). Several other studies have also grouped species of the I- and $\mathrm{Xu}$ genomes [41], using sequences from three nuclear regions DMC1, EF-G and ITS; and the vrs1 locus [42].
In the clade of Triticum species, the hexaploid and tetraploid wheats allelic data were separated into their genomes. A closer association was observed between the $\mathrm{B}-$ and D-genome and tetraploid species were closely related to hexaploid species, which is in agreement with a previous analysis based on wheat EST-SSR data [23].

\section{Conclusion}

Our study shows the utility of barley EST-SSR for the genetic analysis of $H$. chilense, with a remarkably high level of polymorphism within this species. It highlights a reliable and efficient way of obtaining microsatellite markers for wild relatives of a major crop. The transferred markers have shown to be useful for phylogenetic studies among the Triticeae species, and to anchor the H. chilense genome within the wheat-barley framework using Brachypodium as a root genome. The availability of additional sets of mapped EST-derived SSR markers for barley and other Triticeae genomes will assist the development of molecular maps for $H$. chilense and its integration into the genomic network of grass species.

\section{Authors' contributions}

AC carried out most of the molecular work and drafted the manuscript. RKV, HB, GD and PH were involved in designing and planning the work and interpreting the results. HB, RKV, GD and AG edited the manuscript critically. PH and AG conceived the study. PH coordinated the study and helped to draft the manuscript. All authors have read and approved the final manuscript.

\section{Acknowledgements}

Financial support from the Spanish Ministry of Science and Technology, Projects AGL2003-0720 and AGL2006-12550, is acknowledged. We thank Prof. A. Martin (IAS-CSIC, Spain) and Dr. N. Stein (IPK, Germany) for kindly providing plant material. Technical assistance for the capillary electrophoresis separation of SSR fragments at the SCAI (University of Cordoba, Spain) is acknowledged.

\section{References}

I. Wang ML, Barkley NA, Yu JK, Dean RE, Newman ML, Sorrells ME, Pederson G: Transfer of simple sequence repeat (SSR) markers from major cereal crops to minor grass species for germplasm characterization and evaluation. Plant Genetic Resources: characterization and utilization 2005, 3:45-57.

2. Bothmer R, Jacobsen N, Baden C, Jørgensen RB, Linde-Laursen I: An Ecogeographical Study of the Genus Hordeum. Systematic and Ecogeographic Studies on Crop Genepools 1995, 7: I-129.

3. Martín A, Martínez C, Rubiales D, Ballesteros J: Tritordeum: triticale's new brother cereal. Triticale: today and tomorrow 1996:57-72.

4. Martín A, Martin LM, Cabrera A, Ramirez MC, Giménez MJ, Rubiales D, Hernandez P, Ballesteros J: The potential of Hordeum chilense in breeding Triticeae species. In Triticeae III Edited by: Jaradat AA. Science Publishers, Enfield, New Hampshire, USA; 1998:377-386.

5. Martín AC, Atienza SG, Ramírez MC, Barro F, Martín A: Male fertility restoration of wheat in Hordeum chilense cytoplasm is associated with $6 \mathbf{H}^{\mathrm{ch} S}$ chromosome addition. Australian Journal of Agricultural Research 2008, 59:206-213.

6. Hernandez P, Dorado G, Cabrera A, Laurie DA, Snape JW, Martin A: Rapid verification of wheat-Hordeum introgressions by direct 
staining of SCAR, STS, and SSR amplicons. Genome 2002, 45:198-203.

7. Hernandez P, Rubio MJ, Martin A: Development of RAPD markers in tritordeum and addition lines of Hordeum chilense in Triticum aestivum. Plant Breeding 1996, I I 5:52-56.

8. Hernandez P, Martín A, Dorado G: Development of SCARs by direct sequencing of RAPD products: a practical tool for the introgression and marker-assisted selection of wheat. Molecular Breeding 1999, 5:245-253.

9. Gale MD, Devos KM: Comparative genetics in the grasses. Proceedings of the National Academy of Sciences 1998, 95:1971-1974.

10. Hernandez P, Hemmat M, Weeden NF, Dorado G, Martín A: Development and characterization of Hordeum chilense chromosome-specific STS markers suitable for wheat introgression and marker-assisted selection. Theoretical and Applied Genetics 1999, 98:72I-727.

II. Hernandez P, Laurie DA, Martín A, Snape JW: Utility of barley and wheat simple sequence repeat (SSR) markers for genetic analysis of Hordeum chilense and tritordeum. Theoretical and Applied Genetics 2002, 104:735-739.

12. Gupta PK, Varshney RK: The development and use of microsatellite markers for genetics and plant breeding with emphasis on bread wheat. Euphytica 2000, I |3:163-185.

13. Varshney RK, Sigmund R, Börner A, Korzun V, Stein N, Sorrells M, Langridge $P$, Graner A: Interspecific transferability and comparative mapping of barley EST-SSR markers in wheat, rye and rice. Plant Science 2005, 168:195-202.

14. Pinto LR, Oliveira KM, Marconi T, Garcia AAF, Ulian EC, de Souza AP. Characterization of novel sugarcane expressed sequence tag microsatellites and their comparison with genomic SSRs. Plant Breeding 2006, I 25:378-384.

15. Gupta PK, Rustgi S, Sharma S, Singh R, Kumar N, Balyan HS: Transferable EST-SSR markers for the study of polymorphism and genetic diversity in bread wheat. Molecular Genetics and Genomics 2003, 270:3I5-323.

16. Decroocq V, Favé MG, Hagen L, Bordenave L, Decroocq S: Development and transferability of apricot and grape EST microsatellite markers across taxa. Theoretical and Applied Genetics 2003, 106:912-922.

17. Cho YG, Ishii T, Temnykh S, Chen X, Lipovich L, McCouch SR, Park WD, Ayres N, Cartinhour S: Diversity of microsatellites derived from genomic libraries and GenBank sequences in rice (Oryza sativa L.). Theoretical and Applied Genetics 2000, 100:713-722.

18. Boches PS, Bassil NV, Rowland Lا: Microsatellite markers for Vaccinium from EST and genomic libraries. Molecular Ecology Notes 2005, 5:657-660.

19. Varshney RK, Graner A, Sorrells ME: Genic microsatellite markers in plants: features and applications. Trends in Biotechnology 2005, 23:48-55.

20. Cordeiro GM, Casu R, McIntyre CL, Manners JM, Henry RJ: Microsatellite markers from sugarcane (Saccharum spp.) ESTs cross transferable to erianthus and sorghum. Plant Science 200I, 160:III5-II23.

21. Gao L, Tang J, Li H, Jia J: Analysis of microsatellites in major crops assessed by computational and experimental approaches. Molecular Breeding 2003, 12:245-26I.

22. Yu JK, La Rota M, Kantety R, Sorrells M: EST derived SSR markers for comparative mapping in wheat and rice. Molecula Genetics and Genomics 2004, 27 I:742-751.

23. Zhang LY, Ravel C, Bernard M, Balfourier F, Leroy P, Feuillet C, Sourdille P: Transferable bread wheat EST-SSRs can be useful for phylogenetic studies among the Triticeae species. Theoretical and Applied Genetics 2006, II 3:407-4I8.

24. Thiel T, Michalek W, Varshney RK, Graner A: Exploiting EST databases for the development and characterization of genederived SSR-markers in barley (Hordeum vulgare L.). Theoretical and Applied Genetics 2003, 106:4I I-422.

25. Varshney RK, Marcel TC, Ramsay L, Russell J, Roder MS, Stein N, Waugh R, Langridge P, Niks RE, Graner A: A high density barley microsatellite consensus map with 775 SSR loci. Theoretical and Applied Genetics 2007, I | 4:1091-1 103.

26. Miller TE, Reader SM, Chapman V: The addition of Hordeum chilense chromosomes to wheat. Induced variability in plant breeding. EUCARPIA Int Symp 1982.
27. Kellogg EA: Relationships of cereal crops and other grasses. Proceedings of the National Academy of Sciences of the United States of America 1998, 95:2005-2010.

28. Cabrera A, Friebe B, Jiang J, Gill BS: Characterization of Hordeum chilense Chromosomes by C-Banding and in-Situ Hybridization Using Highly Repeated DNA Probes. Genome 1995 38:435-442.

29. Varshney RK, Grosse I, Hahnel U, Thiel T, Rudd S, Zhang H, Prasad $M$, Stein N, Langridge P, Graner A: Genetic mapping and physical mapping (BAC-identification) of EST-derived microsatellite markers in barley (Hordeum vulgare L.). Theoretical and Applied Genetics 2006, I I3:239-250.

30. Murray MG, Thompson WF: Rapid isolation of high molecular weight plant DNA. Nucleic Acid Research 1980, 8:432I-4326.

31. Hernandez P, Dorado G, Prieto P, Giménez MJ, Ramírez MC, Laurie DA, Snape JW, Martín A: A core genetic map of Hordeum chilense and comparisons with maps of barley (Hordeum vulgare) and wheat (Triticum aestivum). Theoretical and Applied Genetics 2001, 102: 1259-1264.

32. Jaccard P: Nouvelles recherches sur la distribution florale. Bulletin de la Société Vaudoise des Sciences Naturelles 1908, 44:223-270.

33. Felsenstein J: PHYLIP Phylogeny Inference Package version 3.5c. In Distributed by the author Department of Genetics, University of Washington, Seattle; 1993.

34. Page RDM: Tree View: An application to display phylogenetic trees on personal computers. Computer Applications in the Biosciences 1996, I 2:357-358.

35. Mian RM, Saha MC, Hopkins AA, Wang Z: Use of tall fescue EST. SSR markers in phylogenetic analysis of cool-season forage grasses. Genome 2005, 48:637-647.

36. Kong $\mathrm{Q}$, Xiang C, Yu Z: Development of EST-SSRs in Cucumis sativus from sequence database. Molecular Ecology Notes 2006, 6:1234-1236.

37. Xinquan Y, Peng L, Zongfu H, Zhongfu N, Oixin S: Genetic diversity revealed by genomic-SSR and EST-SSR markers among common wheat, spelt and compactum. Progress in Natural Science 2005, I5:24-33.

38. Liu ZW, Biyashev RM, Maroof MAS: Development of simple sequence repeat DNA markers and their integration into a barley linkage map. Theoretical and Applied Genetics 1996, 93:869-876

39. Tang J, Gao L, Cao Y, Jia J: Homologous analysis of SSR-ESTs and transferability of wheat SSR-EST markers across barley, rice and maize. Euphytica 2006, I5 I:87-93.

40. Zhang LY, Bernard M, Leroy P, Feuillet C, Sourdille P: High transferability of bread wheat EST-derived SSRs to other cereals. Theoretical and Applied Genetics 2005, I I I:677-687.

4l. Blattner FR: Multiple intercontinental dispersals shaped the distribution area of Hordeum (Poaceae). New Phytologist 2006, 169:603-614.

42. Komatsuda T, Tanno K, Salomon B, Bryngelsson T, von Bothmer R Phylogeny in the genus Hordeum based on nucleotide sequences closely linked to the vrs I locus (row number of spikelets). Genome 1999, 42:973-98I.

Publish with Biomed Central and every scientist can read your work free of charge

"BioMed Central will be the most significant development for disseminating the results of biomedical research in our lifetime. "

Sir Paul Nurse, Cancer Research UK

Your research papers will be:

- available free of charge to the entire biomedical community

- peer reviewed and published immediately upon acceptance

- cited in PubMed and archived on PubMed Central

- yours - you keep the copyright 